von Baer extended it to the phenomena of rivers; the above case may be considered as connecting together both classes of phencmena.

Freiburg-im-Breisgau, November 26 D. WETTERHAN

\section{Spectrum of the Electric Light}

WILL you, or one of your spectroscopical contributors, kindly inform me in what respects (if at all) the spectrum of the electric light differs from that of the sun? At a time apparently not far distant from the almost universal application of the electric light, the question I ask is not unimportant, as it, I believe, affects the tolerance of the human eye for other than solar light. It is already well known that much work done by gas-light is by many found prejudicial to their vision, and this may, 1 presume, be caused by the inherent qualities of the light. It will be interesting to me therefore to learn in what respects electric light and gas-light differ from solar, as shown by spectrum analysis.

Reading, November 28 J. HOPKINS WALTERS

\section{A GLIMPSE THROUGH THE CORRIDORS OF TIME ${ }^{1}$}

II.

$\mathrm{A}^{\mathrm{T}}$

$\mathrm{T}$ the remote epoch of which we are speaking the solar tides were very small, as they are at present. Yet, small as they are, there was a particular circumstance which may have enormously increased their importance. The point to which I refer can be illustrated very simply. We have here a weight of $14 \mathrm{lbs}$. freely suspended, and here I have a small wooden mallet which barely weighs half an ounce, yet small as this mallet is, I can make the heavy weight swing by merely giving it blows with the mallet. Let me try. I give the weight blow after blow. I hit it as hard as I can, yet the weight hardly swings. I have not yet been successful. The art of succeeding is merely to time the blows properly; this I am now doing, and you see the weight swings in an arc which is steadily augmenting.

We therefore see that a succession of impulses, in themselves small, can yet produce a great effect when they are properly timed. In the present case the impulses should succeed each other at the same interval as this pendulum requires for one to and fro oscillation. The time therefore depends on the body struck, and not at all on the body which gives the impulses.

Just as this pendulum swings with a definite period so the vibrations of the primæval earth had a certain period appropriate to them. Suppose that the liquid primæval globe were pressed in on two quadrants and drawn out on the two others, and that the pressures were then released. The globe would attempt to regain its original form, but this it could not do at once, any more than the pendulum can at once regain its vertical position; the protruded portions would go in, but they would overshoot the mark, and the globe would thus oscillate to and fro. Now it has been shown that the period of such oscillations in our primitive globe is about an hour and a half, or very close to half the supposed length of the day at that time. The solar tides, however, also have a period half the length of the day. Here then we have a case precisely analogous to the $\mathrm{I} 4 \mathrm{lb}$. weight I have just experimented on. We have a succession of small impulses given which are timed to harmonise with the natural vibrations. Just as the small-timed impulses raised a large vibration in the weight, so the small solar tides on the earth threw the earth into a large vibration. At first these vibrations were small, but at each succeeding impulse the amplitude was augmented until at length the cohesion of the molten matter could no longer resist : a separation took place: one portion consolidated to form

I Lecture delivered at the Midland Institute, Birmingham, on October 24, 188x, by Prof. Robert S. Ball, LL.D., F.R.S., Andrews Professor of Astronomy in the University of Dublin, and Royal Astronomer of Ireland. Contributed by the Author. Continued from p. 82 . our present earth ; the other portion consolidated to form the moon.

There is no doubt whatever that the moon was once quite close to the earth; but we have to speculate as to what brought the moon into that position. I have given you what I believe to be the most reasonable explanation, and I commend it to your attention. There are difficulties about it, no doubt: let me glance at one of them.

I can easily imagine an objector to say, "If the moon were merely a fragment torn off, how can we conceive that it should have that beautiful globular form which we now see? Ought not the moon to have rugged corners and an irregular shape? and ought not the earth to show a frightful scar at the spot where so large a portion of its mass was rent off."

You must remember that in those early times the earth was not the rigid solid mass on which we now stand. The earth was then so hot as to be partially soft, if not actually molten. If then a fragment were detached from the earth, that fragment would be a soft yielding mass. Not for long would that fragment retain an irregular form; the mutual attraction of the particles would draw the mass together. By the same gentle ministrations the wound on the earth would soon be healed. In the lapse of time the earth would become as whole as ever, and at last it would not retain even a scar to testify to the mighty catastrophe.

I am quite sure that in so large and so cultivated an audience as that which I am now addressing, there are many persons who take a deep interest in the great science of geology. I believe however that the geologist who had studied all the text-books in existence might still be unacquainted with the very modern researches which I am attempting to set forth. Yet it seems to me that the geologists must quickly take heed of these researches. They bave the most startling and important bearing on the prevailing creeds in geology. One of the principal creeds they absolutely demolish.

I suppose the most-read book that has ever been written on geology is Sir Charles Lyell's "Principles." The feature which characterises Lyell's work is expressed in the title of the book, "Modern Changes of the Earth and its Inhabitants considered as Illustrative of Geology." Lyell shows how the changes now going on in the earth have in course of time produced great effects. He points out triumphantly that there is no need of supposing mighty deluges and frightful earthquakes to account for the main facts of geology.

Lyell attempts to show that the present action of winds and storms, of rains and rivers, of ice and snow, of waves and tides, will account for the formation of strata, and that the gentle oscillations of the earth's crust will explain the varying distribution of land and water. In this we can to a great extent follow him. I am quite satisfied with the oscillations in the land. If the land rises an inch or two every century in one place and falls to the same extent elsewhere, all that is required has been explained. Nor do I feel at present disposed to question his views as to rivers or to glaciers, to rains or to winds. There is however one great natural agent of which Lyell does not take adequate account. He does not attach enough importance to the tides. No doubt he admits that the tides do some geological work. He even thinks they can do a great deal of work. The sea batters the cliffs on the coasts, and wears them into sand and pebbles. The glaciers grind down the mountains, the rains and frosts wear the land into mud, and rivers carry that mud into the sea. In the calm depths of ocean this mud subsides to the bottom; it becomes consolidated into rocks; in the course of time these rocks again become raised, to form the dry land with which we are acquainted.

The tides, says Lyell, help in this work. Tidal currents aid in carrying the mud out to sea; they aid to a considerable extent in the actual work of degradation, and 
thus contribute their quota to the manufacture of stratified rocks. Such is the modest rôle which Lyell has assigned to the tides, and no doubt the majority of geologists have acquiesced in this doctrine. Nor can there be any doubt that this is a just view of tidal action at present. That it is a just view of tidal action in past times is what I now deny. Lyell did not know-Lyell could not have known - that our tides are but the feeble surviving ripples of mighty tides with which our oceans once pulsated. Introduce these mighty tides among our geological agents, and see how waves and storms, rivers and glaciers, will hide their diminished heads.

I must attempt to illustrate this view of tidal importance in ancient geological times. Let me try by the aid of the tides to explain the great difficulty which every one must have felt in regard to Lyell's theory. I allude to the stupendous thickness of the Palæozoic rocks.

Look back through the Corridors of Time in the manner in which they are presented to us in the successive epochs of geology. We pass rapidly over the brief career of prehistoric man; then through the long ages of Tertiary rocks, when the great mammals were developed; back again to the much earlier period when colossal reptiles and birds were the chief inhabitants of the earth; back again to those still earlier ages when the luxuriant forests flourished that have given birth to the coal-fields; back once more to the age of fishes; back finally to those earliest periods when the lowest forms of life began to dawn in the Palæozoic era.

As we date remote ages astronomically by the distance of the moon, so we date remote ages geologically by the prevailing organic life. It is a great desideratum to harmonise these two chronological systems, and to find out, if possible, what lunar distance corresponds to each geological epoch. In the whole field of natural science there is no more noble problem. Take, for example, that earliest and most interesting epoch when life perhaps commenced on the earth, and when stratified rocks were deposited five or tea miles thick, which seem to have contained no living forms bigher than the humble Eozoon, if even that were an organised being. Let us ask what the distance of the moon was at the time when those stupendous beds of sediment were deposited in the primæval ocean. We have in this comparison every element of uncertainty except one. The exception is, however, all important. We know that the moon must have been nearer to the earth than it is at present. There are many very weighty reasons for supposing that the moon must have been very much nearer than it is now. It is not at all unlikely that the moon may then have been situated at only a small fraction of its present distance. My argument is only modified, but not destroyed, whatever fraction we may take. We must take some estimate for the purpose of illustration. I have had considerable doubts what estimate to adopt. I am desirous of making my argument strong enough, but I do not want to make it seem exaggerated. At present the moon is 240,000 miles away; but there was a time when the moon was only one-sixth part of this, or say 40,000 miles away. That time must have corresponded to some geological epoch. It may have been earlier than the time when the Eozoon lived. It is more likely to have been later. I want to point out that when the moon was only 40,000 miles away, we had in it a geological engine of transcendent power.

On the primitive oceans the moon raised tides as it does at present ; but the 40,000-mile moon was a far more efficient tide-producer than our $240,000-$ mile moon. The nearer the moon the greater the tide. To express the relation accurately we say that the efficiency of the moon in producing tides varies inversely as the cube of its distance. Here then we have the means of calculating the tidal efficiency for any moon distance. The 40,000-mile moon being at a distance of only one sixth of our present moon's distance, its tidal efficiency would be increased $6 \times 6 \times 6$ fold. In other words, when our moon was only 40,000 miles away it was 216 times as good a tideproducer as it is at present.

The heights to which the tides rise and fall is so profoundly modified by the coasts and by the depth of the sea, that at present we find at different localities tides of only a few inches and tides of 60 or 70 feet. In ancient times there were no doubt also great varieties in the tidal heights, owing to local circumstances. To continue our calculation we must take some present tide. Let us discard the extremes just indicated and take a moderate tide of 3-feet rise and 3-feet fall as a type of our present tides. On this supposition what is to be a typical example of a tide raised by the 40,000 mile moon? If the present tides be 3 feet, and if the early tides be 216 times their present amount, then it is plain that the ancient tides must have been 648 feet.

There can be no doubt that in ancient times tides of this amount and even tides very much larger must have occurred. I ask the geologists to take account of these facts, and to consider the effect-a tidal rise and fall of 648 feet twice every day. Dwell for one moment on the sublime spectacle of a tide of 648 feet high, and see what an agent it would be for the performance of geological work! We are now standing, I suppose, some 500 feet above the level of the sea. The sea is a good many miles from Birmingham, yet if the rise and fall at the coasts were 648 feet, Birmingham might be as great a seaport as Liverpool. Three-quarters tide would bring the sea into the streets of Birmingham. At high tide there would be about I50 feet of blue water over our heads. Every house would be covered, and the tops of a few chimneys would alone indicate the site of the town.

In a few hours more the whole of this vast flood would have retreated. Not only would it leave England high and dry, but probably the Straits of Dover would be drained, and perhaps even Ireland would in a literal sense become a member of the United Kingdom. A few hours pass, and the whole of England is again inundated, but only again to be abandoned.

These mighty tides are the gift which astronomers have now made to the working machinery of the geologist. They constitute an engine of terrific power to aid in the great work of geology. What would the puny efforts of water in other ways accomplish when compared with these majestic tides and the great currents they produce?

In the great primæval tides will probably be found the explanation of what has long been a reproach to geology. The early palæozoic rocks form a stupendous mass of ocean-made beds which, according to Prof. Williamson, are twenty miles thick up to the top of the silurian beds. It has long been a difficulty to conceive how such a gigantic quantity of material could have been ground up and deposited at the bottom of the sea. The geologists said, "The rivers and other agents of the present day will do it if you give them time enough." But unfortunately the mathematicians and the natural philosophers would not give them time enough, and they ordered the geologists to " hurry up their phenomena." The mathematicians had other reasons for believing that the earth could not have been so old as the geologists demanded. Now, however, the mathematicians have discovered the new and stupendous tidal grinding-engine. With this powerful aid the geologists can get through their work in a reasonable period of time, and the geologists and the mathematicians may be reconciled.

I have here a large globe to represent the earth, and a small globe suspended by a string to represent the moon. At the commencement of the history the two globes were quite close; they were revolving rapidly, and the moon was constantly over the same locality on the primæval earth. I do not know where that locality was; it was probably the part of the earth from which the moon had 
been detached. No doubt it was somewhere near the equator, but the distinction of land and water had not then arisen. Around the primæval earth the moon revolved in three hours; the earth also revolved in three hours, so that the moon constantly remained over the red region. This I can illustrate by holding the small globe which represents the moon in one hand, and making the large globe which represents the earth revolve by the other.

This state of things formed what is known as unstable dynamical equilibrium. It could not last. Either the moon must fall back again on the earth, and be reabsorbed into its mass, or the moon must commence to move away from the earth. Which of these two courses was the moon to take? The case is analogous to that of a needle balanced on its point. The needle must fall some way, but what is to decide whether it shall fall to the right or to the left? I do nat know what decided the moon, but what the decision was is perfectly plain. The fact that the moon exists shows that it did not return to the earth, but that the moon adopted the other course, and commenced its outward journey.

As the moon recedes, the period which it requires for a journey round the earth increases also. Initially that period was but three hours, and it has increased up until our present month of 656 hours.

The rotation of the earth has been modified by the retreat of the moon. Directly the moon began to retreat the earth was no longer under an obligation to keep the same face thereto. When the moon was at a certain distance the earth made two rotations for every revolution that the moon made. Thus as I carry the small globe round the large globe the latter makes two revolutions for one revalution of the small globe. Still the moon gets further and further away, until the earth performs three, four, or more rotations for each of the moon's revolutions. Do not infer that the rate of the earth's rotation is increasing ; the contrary is the fact. The earth's rotation is getting slower, and so is that of the moon ; but the retardation of the moon is much greater than that of the earth. Even though the rotation of the earth is much more than the primitive three hours, yet that of the moon has increased to several times the rotation of the earth.

The moon recedes still further and further, and at length a noticeable epoch is reached, to which I must call attention. At that epoch the moon is so far out that its revolution takes twenty-nine times as long as the rotation of the earth. The month was then twenty-nine times the day. The duration of the day was less than the present twenty-four hours, but I do not believe it was very much less. The time we are speaking of is not very remote, perhaps only a very few million years ago. The month was then in the zenith of its glory. The month was never twenty-nine times as long as the day before. It has never been twenty-nine times as long as the day since. It will never be twenty-nine times as long as the day again.

Resuming our history, we find the moon still continuing to revolve in an ever-widening circle the length of the month and of the day both increasing. The ratio of the day to the month was still undergoing a change. When the moon was a little further off the earth only revolved twenty-eight times instead of twenty-nine times in one revolution of the moon. Still the velocity of the earth abates until it only makes twenty-seven revolutions in one revolution of the moon. This is an epoch of especial interest, for it is the present time. In the present order of things the moon revolves round the earth once while the earth rotates twenty-seven times. This has remained sensibly true for thousands of years, and no doubt will remain sensibly true for thousands of years to come, but it will not remain true indefinitely. Wondrous as are the changes which have occurred in times past, not lesi wondrous are the changes which are to occur in time to come. The tides have guided our gropings into the past; they will continue to guide our researches to make a forecast of the future.

Further and further will the moon retreat, and more and more slowly will the earth revolve. But we shall not pause at intervening stages; we shall try to sketch the ultimate type to which our. system tends. In the dim future, many millions of years distant, the final stage will be approached. As this stage draws nigh, the rotation of the earth will again approach to equality with the revolution of the moon. From the present month of twentyseven days we shall pass to a month of twenty-six days, of twenty-five days, and so on, until eventually we shall reach a month of two days, and lastly a month of one day. When this state has been attained the earth will constantly turn the same region towards the moon. I do not know what is the locality on the earth which is destined for this distinction.

Here you see that the first state and the last state of the earth-moon history are in one sense identical. In each case the same face of the earth is constantly directed towards the moon. In another way, how different are the first stage and the last. At the beginning the day and the month were both equal, and they were each three hours. At the end the day and the month will be again equal, but they will each be 1400 hours. The moon will then go round the earth in I 400 hours, while the earth will rotate on its axis in the same time. In other words, the day is destined in the very remote future to become as long as fifty-seven of, our days. This epoch will assuredly come if the universe lasts long enough. When it has come it will endure for countless ages. It would endure for ever if the earth and the moon could be isolated from all external interference.

We heard a great deal a few years ago about the necessity of shortening the hours of labour. I wish to point out that the social reformers who are striving to shorten the hours of labour are pulling one way, while the moon is pulling the other. The moon is increasing the length of the day. The change will be very gradual, but none the less is it inevitable. Where will the nine-hours' movement be when the day has increased to I 400 hours? This will be a very serious matter, and there is only one way by which it can be avoided. The question is one rather for engineers than for astronomers; but I cannot help throwing out a suggestion. My advice is: Anchor the moon, and keep it from going out. If you can do this, and if you can also provide a brake by which the speed of the moon can be controlled, then you will be able for ever to revel in the enjoyment of a twentyfour-hour day.

Should this engineering feat never be accomplished, then we have only the I400-hour day to look forward to. Nor is there anything untoward in the prospect, when we take natural selection as our comforter. By natural selection man has become exactly harmonised with his present environment. No doubt natural selection moves at a dignified pace, but so in all truth does tidal evolution. Natural selection and tidal evolution have advanced pari passu through all the past millions of geological time. They will advance pari passu through all the ages yet to come. As the day lengthens, so will man's nature gradually change too, without any hardship or inconvenience. All that is necessary is plenty of time. Should we think it a hardship that our children should have a day of twenty-four hours and one second instead of twenty-four hours? That the day enjoyed by our grandchildren should be a second longer than the day of our children? That the day of our great-grandchildren should be a second longer still, and so on continually? This would be no inconvenience whatever. No one except the astronomers would be able to detect the change, and daily life would be unaltered. Yet, carry on this process for only i 50 million years, and we shall find that the whole change of the day $f$ 
twenty-four hours to 1400 hours has been accomplished. The actual rate of change is indeed much less than this, and is at present so small that astronomers can hardly even detect it.

Our remote posterity will have a night 700 hours long, and when the sun rises in the morning 700 hours more will elapse before he can set. This they will find a most suitable and agreeable arrangement. They will look back on our short periods of rest and short periods of work with mingled curiosity and pity. Perhaps they will even have exhibitions of eccentric individuals able to sleep for eight hours, work for eight hours, and play for eight hours. They will look on such curiosities in the same way as we look on the man who undertakes to walk a thousand miles in a thousand hours.

I am beyond all things anxious to give you the impression that I am not indulging in any mere romance. No doubt the various figures I have mentioned are but estimates. They may be found to require correction-perhaps large correction; but the general outline of the theory must be true. Should any traces of doubt still linger in the mind of some prejudiced person, let me finally dissipate them. Perhaps some caviller may say, Where are the proofs of all this action of the tides? How do you know that the tides are sufficiently powerful to produce such changes? I believe I have shown this abundantly, but some people require a great deal of conviction. I have therefore kept my best argument for the end.

For an overwhelming proof of tidal efficiency I shall summon the heavens themselves to witness, and I shall point to the stupendous task which tides have already accomplished. As the moon has made and is making tides on the earth, so the earth once raised tides on the moon. These tides have ceased for ages; their work is done; but they have raised a monument in the moon to testify to the tidal sufferings which the moon has undergone. To that monument I now confidently appeal. The moon being much smaller than the earth, the tides on the moon produced by the earth must have been many times as great as the tides on our earth produced by the moon. It matters not that the moon now contains no liquid ocean. Nor does it matter whether the moon ever had a liquid ocean. In very ancient days the moon was not the hard, rigid mass which it now appears. Time was when the volcanoes raged on the moon with a fury which nothing on our earth at present can parallel. The moon was then in a soft or a more or less fluid condition, and in this viscous mass the earth produced great tides.

Great tides in truth they were, for the earth is eighty times as heavy as the moon. On the other hand, the moon is only one-fourth the diameter of the earth; so that the actual height of the tides on the moon would be still many times as great as the tides on the earth. When the moon was nearer to us, as it was in early ages, those tides were still greater. Think for one moment of what a lunar tidal wave of such magnitude would be capable. This wave is perhaps of molten lava; it would tear over the surface with terrific power, and anything that friction could accomplish that great current would do. That tidal current has done its work; even if the moon were fluid at the present day it could no longer be distracted by tides. Remember, it is not the mere presence of the tide which produces friction. It is the action of the tide in rising and in falling which accomplishes the work. If, therefore, the moon moved so that it was always high tide at the same place, the tides could produce no further effect. The spot where the tide is high on the moon is the spot which is towards the earth. It hence follows that the action of the tides will cease when the moon constantly directs the same face to the earth. The moon has thus at length gained a haven of rest from a tidal point of view. No doubt the moon has a high tide and it has a low tide, but those tides no longer $\mathrm{ebb}$ and flow: the moon has succumbed to the incessant action of friction, and has assumed the only attitude which can relieve it from incessant disturbance.

For many centuries it had been an enigma to astronomers why the moon should always turn the same face to the earth. It could be shown that there were many million chances to one in favour of this being due to some physical cause. The ordinary theory of gravitation failed to explain the cause. Every one had noticed this phenomenon. Yet the explanation was never given till lately. It was Helmholtz who showed that this was a consequence of ancient tides, and this simple and most satisfactory explanation has been universally accepted. The constant face of the moon is a living testimony to the power of the tides. What tides have accomplished on the moon is an earnest of what tides will accomplish on the earth.

In the great conflict of the tides the earth has already conquered the moon, and forced the moon to render perpetual homage as a token of submission. Remember, however, that the earth is large, and the moon is small. Yet small though the moon is, it gallantly struggles on. "You have forced me," cries the moon to the earth, "to abandon the rotation with which I was originally endowed; you have compelled me to rotate in the manner you have dictated. I will have my revenge. It is true I am weak, but I am unrelenting; day by day I am exhausting you by the tides with which I make you throb. The time will assuredly come, though it may not be for millions of years, when you shall be forced to make a compromise. When that compromise is made the turmoils of the tides will cease ; our mutual movements will be adjusted. With equal dignity we shall each rotate around the other; with equal dignity we shall each constantly bend the same face to the other."

There is another point to be considered. We must not forget that there is a sun in the heavens as well as a moon. The sun also produces tides in the earth. Those tides were much smaller than the lunar tides, so that we could afford to neglect them. But we have seen that the lunar tides will gradually decrease to nothing. It behoves us then to consider what the solar tides can effect which shall be worthy of our attention. In a lecture which I gave here some years ago, I made allusion to the discovery of the satellites of Mars. I mentioned that one of the satellites of Mars presented a phenomenon unparalleled in the solar system. The satellite revolved around Mars in a period of seven hours, while Mars himself rotated on his axis in a period of twenty-four hours. We here actually find the moon of Mars rotating around Mars in much less than one of Mars' own days. This was a most curious and unexpected circumstance, but the observations of the discoverer, Asaph Hall, placed the great fact beyond any doubt. The mystery has now been explained. It is due to the action of the solar tides on Mars. Nay more, we can actually foresee that at some incredibly remote future time our earth and moon are destined to present the same movements which have seemed so anomalous in Mars.

Left to themselves, the earth and the moon would have remained for ever in the condition of compromise. The moon would have revolved round the earth in 1400 hours. The earth would have rotated on its axis in 1400 hours also. But now the solar tides intervene. They have little effect upon the moon; it revolves as before, but the solar tides begin to retard the earth still further. Instead of a period of 1400 hours, the earth will have a still longer day, so that finally the moon revolves more rapidly around the earth than the earth rotates on its axis.

It seems to me that the episode I have mentioned is one of the most interesting in the whole of modern astronomy. We have first a most delicate telescopic discovery of the tiny satellite of Mars and of its anomalous movements. We then have a beautiful explanation of how 
this anomalous motion has arisen from the action of solar tides. Finally we have in this miniature system of Mars a foreshadowing of the ultimate destiny of our earth and our moon.

Do I say the ultimate destiny? Nothing is ultimate in nature. The moon and the earth would have come to an amicable and a final agreement had they been let alone. But now the sun has intervened and disturbed the earth's rotation. The truce once broken, the moon again produces tides on the earth, the earth reacts on the moon, and a whole chain of complicated movements are the consequence. I shall not now attempt to trace the further progress of events.

I have dealt with very large figures in this lecture, and perhaps I have taxed your imagination by my demands that you should conceive of periods of tens of millions of years. Yet after all let us look at the results in their true proportion, compared with the universe in which our lot has been cast.

Truly we have been engaged with a very trifling matter. Is not our earth one of the most insignificant bodies in the universe? And our moon is much smaller still. Nor is it even the life-history of our earth that we have been considering, it is merely a brief episode in that history. What are the periods of time we have been discussing when compared with those infinitely longer periods during which the solar system has been evolved? Even the solar system is but one out of one hundred million such systems, each of which has its own life-history. Viewed in their true proportions, the phenomena I have described are but of infinitesimal importance, and the time they have occupied is merely ephemeral.

No doubt we have only dwelt upon the tides on the earth and the tides in the moon, which have been of such infinite importance. But do not suppose that tides are confined to the earth and to the moon. So far as we know, every body in the universe is capable of producing, and actually does produce, tides in every other body. Every planet throbs in response to the tides produced in it by every other planet. Every star has a distinct tidal wave produced in it by every other star. You may say that such tides are infinitesimal, but you must remember that infinitesimal causes, sufficiently often repeated, can achieve the mightiest effects.

We know that tides have wrought our solar system into its present form; and are we to say that the wondrous powers of the tide have no grander scope for their exercise? I prefer to believe that tides operate far and wide through the universe, and that in the recognition of the supreme importance of tidal evolution we mark a great epoch in the history of physical astronomy.

\section{POPULAR NATURAL HISTOR $Y^{1}$}

$\mathrm{T} \mathrm{HE}$ present volume of this finely illustrated work finishes the account of the Verteprates with the history of the Fishes, and gets over as well an immense mass of the Invertebrates. The story of the Fishes is contributed by Prof. H. G. Seeley, who, in the limited compass of 150 pages, of which about one-sixth is occupied with figures, has given a very fair and comprehensive notice of this class. The Fishes are the only primary division of the Vertebrata which live in water, and have no representatives passing their lives upon land or in the air. This condition of existence is probably the cause of the close correspondence in bodily form in the majority of fishes, which progress through the water chiefly by movements of the tail, and use the fins as organs with which to steer a path. "Clear as is the idea which rises in the mind at the mention of a fish, the multitude of forms which fishes exhibit are greater, perhaps, than those to be found in any of the other great groups of Vertebrate

× “Cassell's Natural History." Edited by P. Martin Duncan, M.B., F.R.S. Vol, v., illustrated. (London: Cassell, Petter, Galpin, and Co., r881. animals described in the previous four volumes of this series. The slender form of the lamprey or eel contrasts with the expanded body of the turbot or the plaice; the short deep form of the sun-fish is unlike the broad, flattened, and long-tailed skate ; the sea-horses, when attached to sea-weeds by their prehensile tails, at first sight present none of the familiar characteristics of fishes. The flyingfish, which have the fins so expanded as to serve some of the purposes of wings, present a remarkable contrast to the spheroidal spiny body of the globe-fish, while the hammer-headed shark exhibits a form of body in some respects more singular still. When we turn to details of proportion and structure, and contrast the shapes of the head or of the tail, the variety among fishes is altogether exuberant."

As an illustration of the woodcuts to be found plentifully in this volume, we select a sea-horse some time since described by Dr. Günther, the strange bizarre form of which will at once attract attention. The illustration is a very fair copy of the beautifully-drawn figure of Mr. Ford in the Proceedings of the Zoological Society of London for 1865 , and represents, of the natural size, a specimen of Phyllopteryx eques from South Australia. "There is no doubt," writes Dr. Günther, "that these fish attach themselves with the prehensile end of their tails to stems of sea-weed and other objects; and when they are in the vicinity of sea-weed of a similar colour to themselves, their resemblance to it must be so great that they would easily escape being observed by their enemies." We fancy that Prof. Seeley is wrong in stating that, "as the name implies, this fish has very much the aspect of a moving plant." The idea in Swainson's mind was doubtless nearer to the actual meaning of the words he formed the generic title from-that of leaf-winged-and we may venture to call Dr. Günther's species the Leaf-finned Sea-horse.

The section on Fossil Fishes is very short, but a great deal of information is contained therein. "A large proportion of fossil fishes belong to the division Palæichthyes. This group comprises most of the fishes which have been met with in the primary rocks and many of those found in the Secondary strata; but in Tertiary deposits the Teleostean division is quite as well represented in the geological formations as in existing seas. There is no evidence of any gradual succession of fishes in the order of increased complicity of structure, as the deposits in which they occur approach nearer to the present day, and there is no reason to suppose that the oldest fishes known were the first that appeared upon the earth. The earliest fishes discovered were met with in the Lower Ludlow rocks, which form the upper part of the Silurian strata. The most ancient genus is Scaphaspis, a small bucklerheaded fish, which had the body covered with scales. Many allied genera are found in the overlying Old Red Sandstone, in which fishes appear in extraordinary variety. Among the allies of Scaphaspis are Pteraspis, Cephalaspis, \&c., some of which range down to the Silurian rocks. Near to these fishes must be placed Coccosteus, Pterichthys, and the immense American fossil of Devonian age named Dinichthys. These fishes are thought to be related to Ganoids and Sharks, but in external form they more closely approximate to Loricaria, though the tail is heterocercal. They form a distinct group named Placodermi."

While four volumes and a goodly portion of a fifth are devoted to the Vertebrata, there are not wanting signs that the immense divisions of the animal kingdom here grouped as Invertebrata are to be treated of after the usual stereotyped fashion, and that at most one further volume will bring this series to a close. The Invertebrata, we are told, are divided into great types, or groups, which are (I) the Mollusca; (2) the Arthropoda; (3) the Vermes; (4) the Echinodermata; (5) the Zoophyta; and (6) Protozoa. "These great divisions are not exactly 